\title{
Comparison of PD Activity for Different Solid Dielectrics Having Cubical Void using MATLAB Simulink
}

\author{
D M Srinivasa ${ }^{1}$, Chandrakanth $\mathrm{B}^{2}$, Flavia Valentina ${ }^{3}$, Pooja B $\mathrm{S}^{4}$, Suneel ${ }^{5}$ \\ Assistant Professor, E\&E Department, PESCE, Mandya, Karnataka, India ${ }^{1}$ \\ UG Student, E\&E Department, PESCE, Mandya, Karnataka, India 2, 3, 4,5
}

\begin{abstract}
An important tool for improving the reliability of high voltage (HV) insulation systems are partial discharge (PD) measurements. Partial Discharge (PD) that damages insulation by gradual erosion is major source of insulation failure. In electrical engineering, partial discharge (PD) is a localized dielectric breakdown of a small portion of a solid or fluid electrical insulation system under high voltage stress, which does not bridge the space between two conductors. So, an important tool for improving the reliability of HV insulation systems are partial discharge (PD) measurements. Accurate simulating of PD is more important for insulation study. In this paper, the mechanism of PD has been simulated by using MATLAB simulink.
\end{abstract}

Keywords: Permittivity $\left(\varepsilon_{\mathbf{r}}\right.$ ), Partial Discharge (PD), Void model, MATLAB, Solid insulation sample, HV (high voltage), $\mathrm{Ca}, \mathrm{Cb}, \mathrm{Cc}$.

\section{INTRODUCTION}

In $\mathrm{HV}$ power system, the insulating tools used, is not pure in every aspect and holds impurities. The presence of air particles is a major contaminations in insulating equipments and extremely unwanted as it causes a local region inside the insulator which is very weak as compared to its surroundings. The types of faults created because of insulation breakdown as an outcome of localized electrical strain inside the insulation, whether solid or fluids is broadly pervasive and it is known as partial discharge (PD). The high voltage equipments have to be tested for PD to ensure its present quality.

\section{PARTIAL DISCHARGE}

Partial discharge is defined as a localized electrical discharge that partially bridges the insulation gap between the electrodes and which may or may notoccur adjacent to a conductor[1]. The high voltage equipments have to be tested for PD to showsits present quality. PD technology used for diagnosing the state of such equipment has been of extreme importance. Thus, exactness should be increased and uncertainty should be decreased in the measurement of PD. The reliability of the measurement results is strongly depends on the calibration of the PD measurement system .A PD detector is being modeled in SIMULINK to generate PD pulses having identified charge and maximum amplitude.

\section{Sample Preparation:}

Presence of void inside the solid dielectric insulator with a cubical void inside is considered having the dimensions $100 \mathrm{~mm}, 50 \mathrm{~mm}, 40 \mathrm{~mm}$. The dimension of the cubical void considered is $10 \mathrm{~mm}, 5 \mathrm{~mm}, 4 \mathrm{~mm}$. As the electrical circuit model used in the simulation consists of three capacitors $\mathrm{Ca}, \mathrm{Cb}, \mathrm{Cc}$. Two are connected in series with parallel to the other. The series capacitances are the capacitance of the void and the capacitance of the healthy insulator in series with the void. The parallel capacitor to the above two is the capacitance of the remaining parts of the insulator.

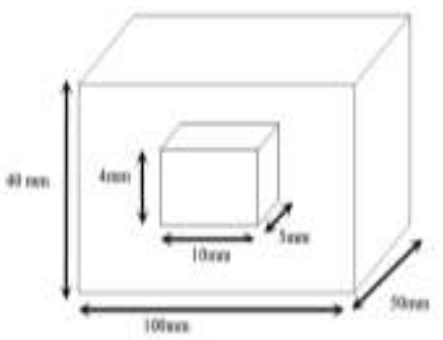

Fig1: void model of Solid insulator. 
The capacitors mentioned above in the void model is shown below with equivalent circuit of connections of $C_{a}, C_{b}, C_{c}$.

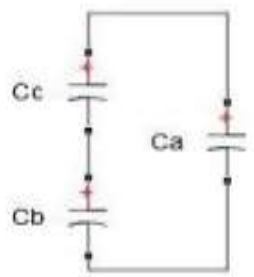

Fig2: equivalent circuit of the test object

The values of the Capacitors can be found using the formulas given below for a cubical void:

$\mathrm{C}_{\mathrm{a}}=\frac{\varepsilon_{0} * \varepsilon_{\mathrm{r}} * \mathrm{~A}}{\mathrm{~d}}$

$\mathrm{C}_{\mathrm{b}}=\frac{\varepsilon_{0} * \varepsilon_{\mathrm{r}} * \mathrm{~A}}{\mathrm{~d}-\mathrm{t}}$

$\mathrm{C}_{\mathrm{c}}==\frac{\varepsilon_{0} * \mathrm{~A}}{\mathrm{t}}[5]$

Where, $\varepsilon_{0}=$ absolute permittivity $=8.854 * 10^{-12}$ $\varepsilon_{\mathrm{r}}=$ relative permittivity $[8]$

\begin{tabular}{|c|l|c|c|}
\hline Capacitor & Epoxy Resin & Rubber & Teflon \\
\hline $\mathrm{C}_{\mathrm{a}}$ & $3.873 * 10^{-14}$ & $3.3202 * 10^{-14}$ & $2.213 \times 10^{-14}$ \\
\hline $\mathrm{C}_{\mathrm{b}}$ & $4.304 * 10^{-14}$ & $3.689 * 10^{-14}$ & $2.459 \times 10^{-14}$ \\
\hline $\mathrm{C}_{\mathrm{c}}$ & $1.1067 * 10^{-13}$ & $1.1067 * 10^{-13}$ & $1.1067 * 10^{-13}$ \\
\hline
\end{tabular}

\section{EXPERIMENTAL SETUP}

For the above calculated values of capacitances are used to get the required partial discharge characteristics. The equivalent circuit of having a cubical shape void for different solid dielectrics is taken to evaluate the partial discharge characteristics. The Simulink model for detecting partial discharge characteristics is shown in figure 3.

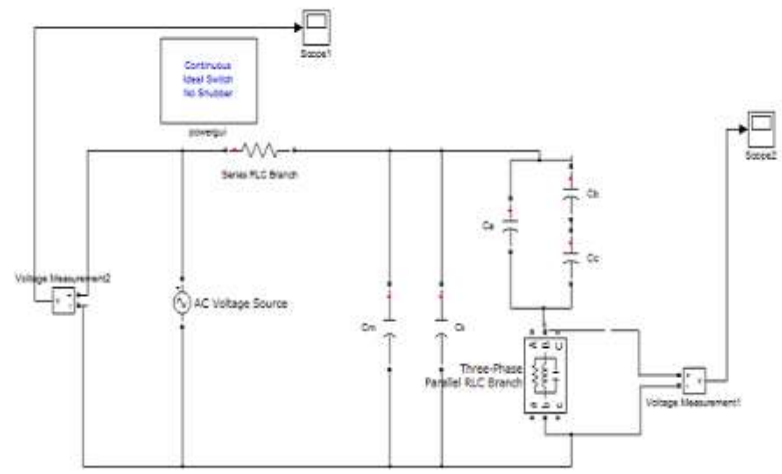

Fig3: Simulink model[4]

Generally $\left(\mathrm{C}_{\mathrm{c}}>>\mathrm{C}_{\mathrm{b}}>>\mathrm{C}_{\mathrm{a}}\right)$ for a cubical void. The Simulink model for obtaining partial discharge characteristics is shown in figure $3 . \mathrm{Ca}, \mathrm{Cb}$ and $\mathrm{Cc}$ together constitutes the test object. $\mathrm{Cm}$ refers to the measuring capacitor and $\mathrm{Ck}$ refers to the value of coupling capacitor.

The circuit model drawn in Fig.3 is simulated using MATLAB software. When the voltage across the dielectric $\mathrm{V}_{\mathrm{a}}$ is increased thereby the voltage across the cavity $\mathrm{V}_{c}$ also increases. When $\mathrm{V}_{\mathrm{c}}$ reaches breakdown voltage, discharge in the void occurs. The voltage across the sample at which discharges begin to occur is called Inception voltage[4]. 


\section{International Journal of Innovative Research in} Electrical, Electronics, Instrumentation and Control Engineering

\section{ISO 3297:2007 Certified}

Vol. 5, Issue 5, May 2017

In Fig. 4 the partial discharge pulses in $\mu \mathrm{v}$ are seen in scope 2 which is connected through voltage measurement 1 across matching impedance. The applied input voltage is measured through voltage measurement 2 and witnessed in scope 1.

In this study the value of void model and the other HV equipment for the measurement of PD inside the solid insulation is taken as depicted below in Table1[6].

Table1.1 shows the permittivity for different dielectrics

Table1. Parameters used in Simulation

\begin{tabular}{|l|l|l|l|}
\hline Parameter & Value & Symbol & Dimension \\
\hline HV Measuring capacitor & 1000 & $\mathrm{Cm}$ & $\mathrm{pF}$ \\
\hline Coupling Capacitor & 1000 & $\mathrm{Ck}$ & $\mu \mathrm{F}$ \\
\hline Relative Permittivity & $8.854 \times 10^{-12}$ & $\varepsilon_{0}$ & $\mathrm{~F} / \mathrm{m}$ \\
\hline Resistance & 50 & $\mathrm{R}$ & $\Omega$ \\
\hline Inductance & 0.60 & $\mathrm{~L}$ & $\mathrm{mH}$ \\
\hline Capacitance & 0.45 & $\mathrm{C}$ & $\mu \mathrm{F}$ \\
\hline
\end{tabular}

Table1.1 Permittivity of different dielectrics

\begin{tabular}{|l|l|}
\hline Solid Dielectrics & Permittivity $\boldsymbol{\varepsilon}_{\mathbf{r}}$ \\
\hline Epoxy resin & 3.5 \\
\hline Rubber & 3 \\
\hline Teflon & 2 \\
\hline
\end{tabular}

\section{RESULTS AND DISSCUSSIONS}

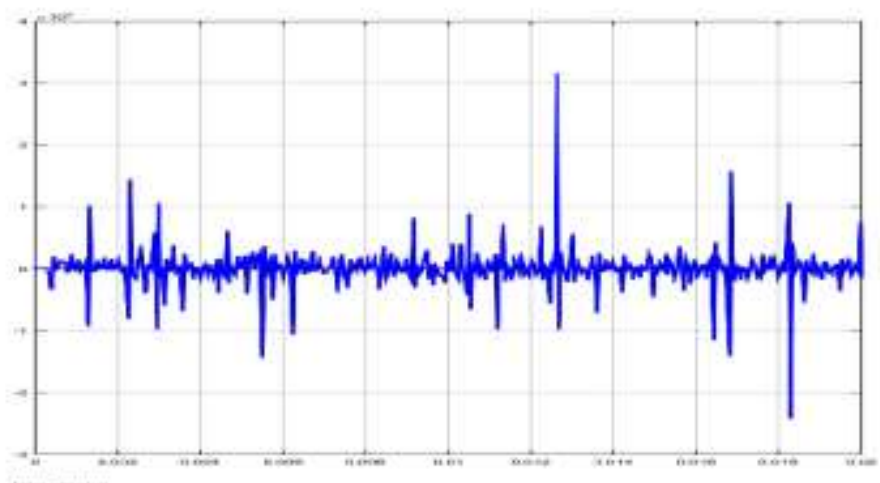

Fig4: Observed Partial discharge pulse at $10 \mathrm{KV}$ of epoxy resin

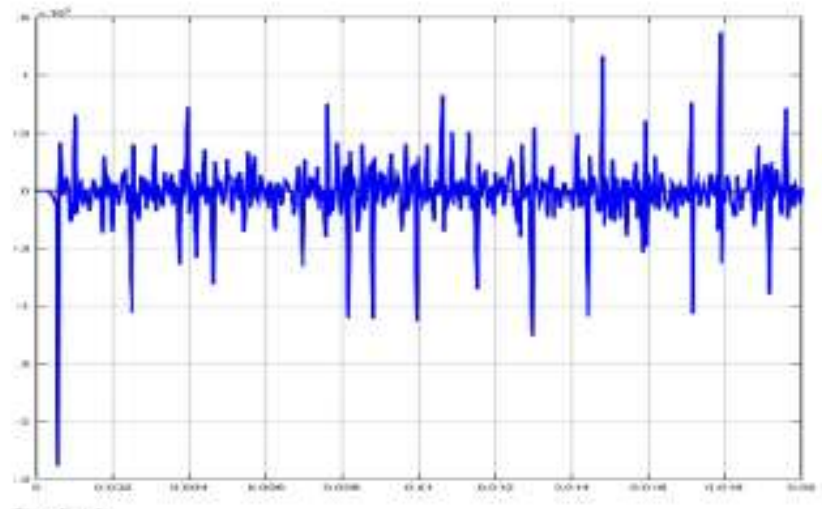

Fig5: Observed Partial discharge pulse at $10 \mathrm{KV}$ of Rubber 


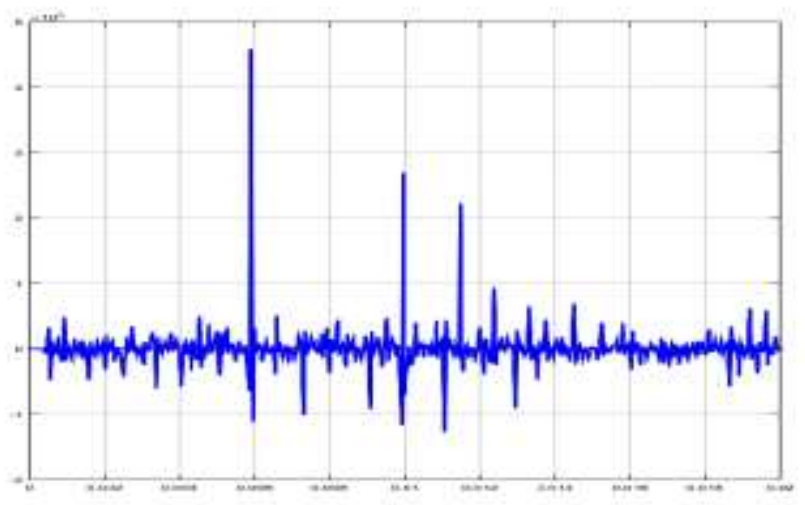

Fig6: Observed Partial discharge pulse at 10KV of Teflon

Fig4,5,6 shows the PD characteristics of output obtained from scope1 for applied voltages of 10KV for Epoxy resin , Rubber ,Teflon. It is observed that at $10 \mathrm{KV}$ the amount of Partial discharge for different solid dielectrics at different dielectrics.The input, output graph of PD characteristics are shown in Fig7,8,9 at voltage 10KV for different dielectrics.

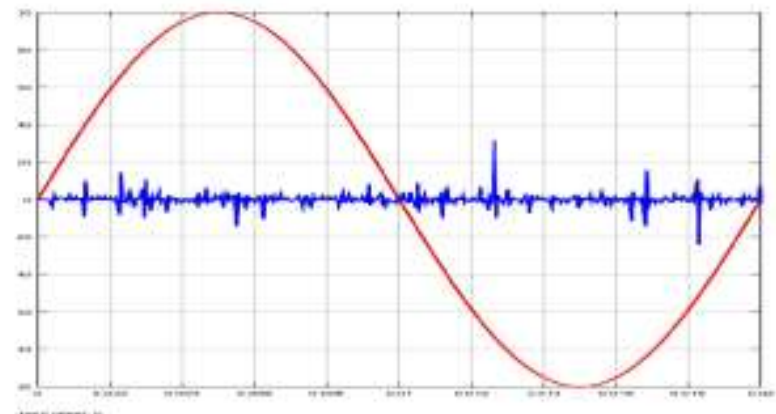

Fig7. PD characteristics along with input at $10 \mathrm{KV}$ for epoxy resin

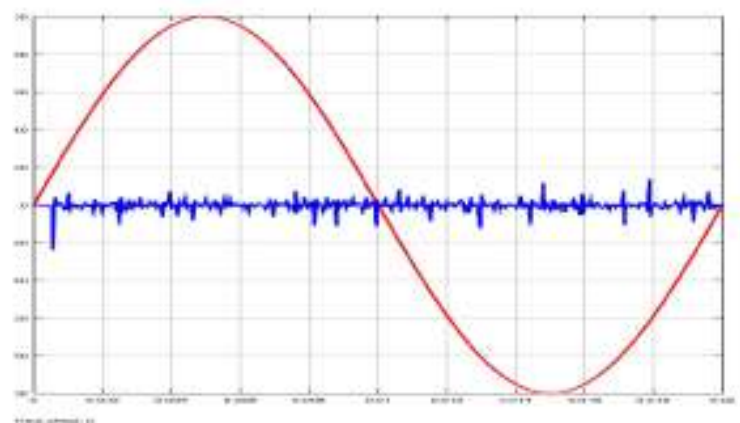

Fig8. PD characteristics along with input at $10 \mathrm{KV}$ for Rubber

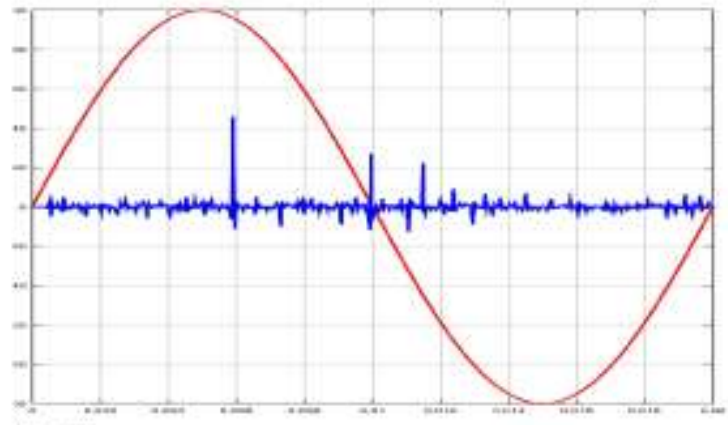

Fig9. PD characteristics along with input at 10KV for Teflon 


\section{International Journal of Innovative Research in} Electrical, Electronics, Instrumentation and Control Engineering

ISO 3297:2007 Certified

Vol. 5, Issue 5, May 2017

The Maximum PD amplitude at different applied voltages is shown in Table2.

Table2.Max.PD amplitude at different applied Voltages for different solid dielectrics

\begin{tabular}{|l|l|l|l|}
\hline \multirow{2}{*}{ Applied voltage in KV } & \multicolumn{3}{|c|}{ Max. PD amplitude in $\mu \mathrm{V}$} \\
\cline { 2 - 4 } & Epoxy resin & Rubber & Teflon \\
\hline 5 & 4.008 & 3.841 & 5.545 \\
\hline 10 & 12.55 & 5.09 & 11.46 \\
\hline 15 & 3.632 & 3.14 & 9.113 \\
\hline 20 & 3.16 & 4.2 & 3.272 \\
\hline 25 & 3.492 & 10.06 & 4.873 \\
\hline 30 & 13.46 & 6.029 & 4.274 \\
\hline
\end{tabular}

For the Table2.The graph of Max. PD amplitude at different applied voltages for different solid dielectrics is shown in Fig10.

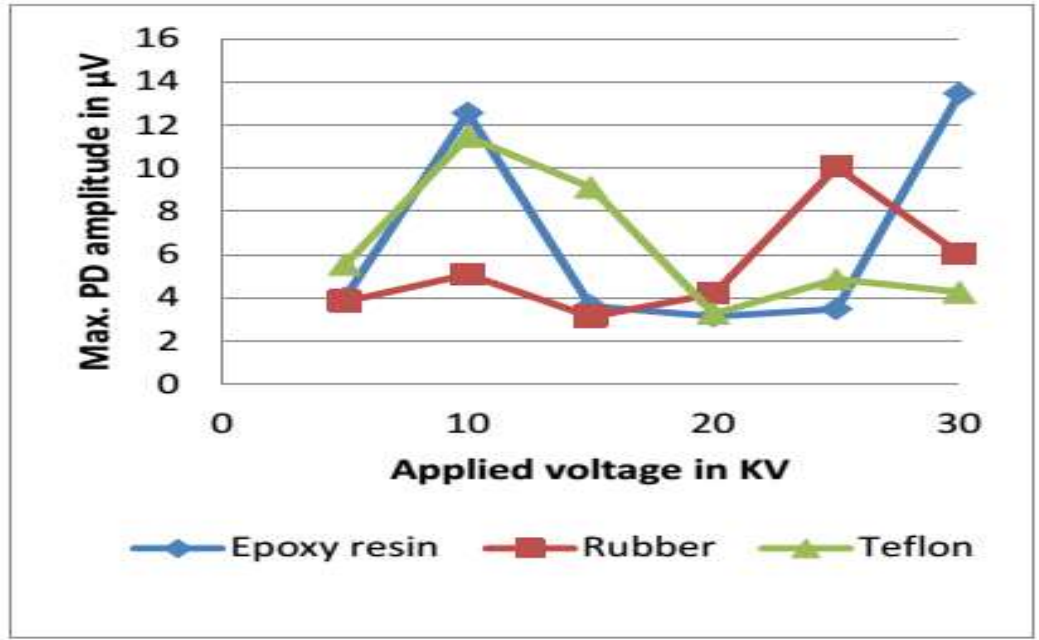

Fig10. Max. PD at different applied voltages for different Solid dielectrics

From the graph of Max.Pd we can that at 30KV the Max. amplitude of Epoxy resin is greater than Rubber and Teflon. The partial discharge pulses are dividing single applied sinusoidal cycle frequency of $50 \mathrm{~Hz}$ into eight equal parts. Each part has $45^{\circ}$ phase angle interval.

The number of PD pulses for every interval is plotted for different applied voltages. Figures $(11,12,13)$ shows graph for number of PD pulses v/s different phase angle for different applied voltages for different solid dielectrics.

Table 3. No. of PD pulse at different applied voltages at different phase angles of Epoxy resin

\begin{tabular}{|l|l|l|l|}
\hline \multirow{2}{*}{$\begin{array}{l}\text { Phase angle in } \\
\text { degree }\end{array}$} & \multicolumn{4}{|l|}{ No.of PD pulses in Epoxy resin } \\
\cline { 2 - 4 } & $5 \mathrm{KV}$ & $10 \mathrm{KV}$ & $15 \mathrm{KV}$ \\
\hline $0-45$ & 12 & 13 & 12 \\
\hline $46-90$ & 14 & 15 & 14 \\
\hline $91-135$ & 15 & 11 & 17 \\
\hline $136-180$ & 13 & 13 & 19 \\
\hline $181-225$ & 20 & 24 & 21 \\
\hline $226-270$ & 19 & 20 & 25 \\
\hline $271-315$ & 15 & 25 & 13 \\
\hline $316-360$ & 2 & 2 & 3 \\
\hline
\end{tabular}



Electrical, Electronics, Instrumentation and Control Engineering ISO 3297:2007 Certified

Vol. 5, Issue 5, May 2017

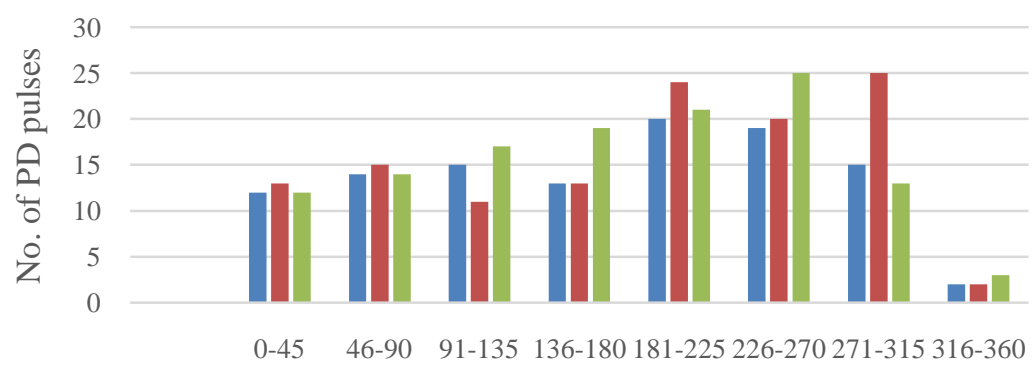

Phase angle in degree

$\square 5 \mathrm{k} \quad \square 10 \mathrm{k} \quad \square 15 \mathrm{k}$

Fig 11. No. of PD pulses at different voltages at Different phase angles ofEpoxy resin

Table4. No of PD pulse at different applied voltages at Different phase angles of Rubber

\begin{tabular}{|l|l|l|l|}
\hline \multirow{2}{*}{ Phase angle in degree } & \multicolumn{3}{|l|}{ No. of PD pulses in Rubber } \\
\cline { 2 - 4 } & $5 \mathrm{KV}$ & $10 \mathrm{KV}$ & $15 \mathrm{KV}$ \\
\hline $0-45$ & 16 & 9 & 10 \\
\hline $46-90$ & 17 & 22 & 12 \\
\hline $91-135$ & 10 & 12 & 10 \\
\hline $136-180$ & 22 & 31 & 23 \\
\hline $181-225$ & 34 & 30 & 23 \\
\hline $226-270$ & 20 & 16 & 22 \\
\hline $271-315$ & 10 & 17 & 21 \\
\hline $316-360$ & 4 & 5 & 8 \\
\hline
\end{tabular}

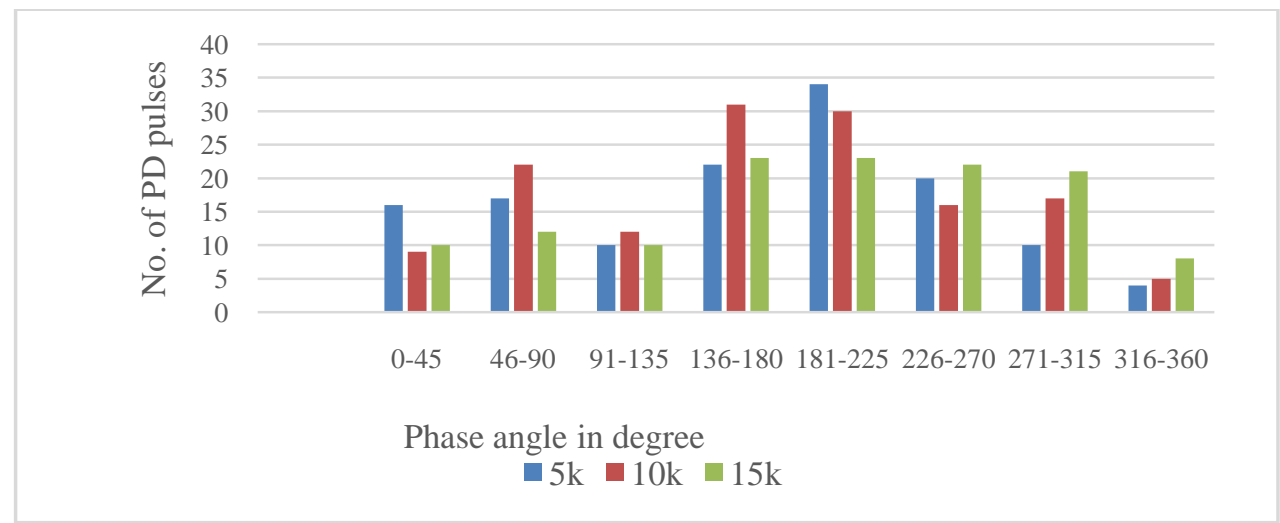

Fig 12. No of PD pulse for different applied voltages at different phase angles of Rubber

Table5. No. of PD pulse at different phase angles at different applied voltages of Teflon

\begin{tabular}{|l|l|l|l|}
\hline \multirow{2}{*}{ Phase angle in degree } & \multicolumn{3}{|l|}{ No. of PD pulses in Teflon } \\
\cline { 2 - 4 } & $5 \mathrm{KV}$ & $10 \mathrm{KV}$ & $15 \mathrm{KV}$ \\
\hline $0-45$ & 11 & 11 & 15 \\
\hline $46-90$ & 19 & 16 & 13 \\
\hline $91-145$ & 20 & 22 & 13 \\
\hline $146-180$ & 14 & 20 & 19 \\
\hline $181-225$ & 21 & 22 & 30 \\
\hline $226-270$ & 10 & 16 & 17 \\
\hline $271-315$ & 17 & 11 & 14 \\
\hline $316-360$ & 7 & 9 & 4 \\
\hline
\end{tabular}


Vol. 5, Issue 5, May 2017

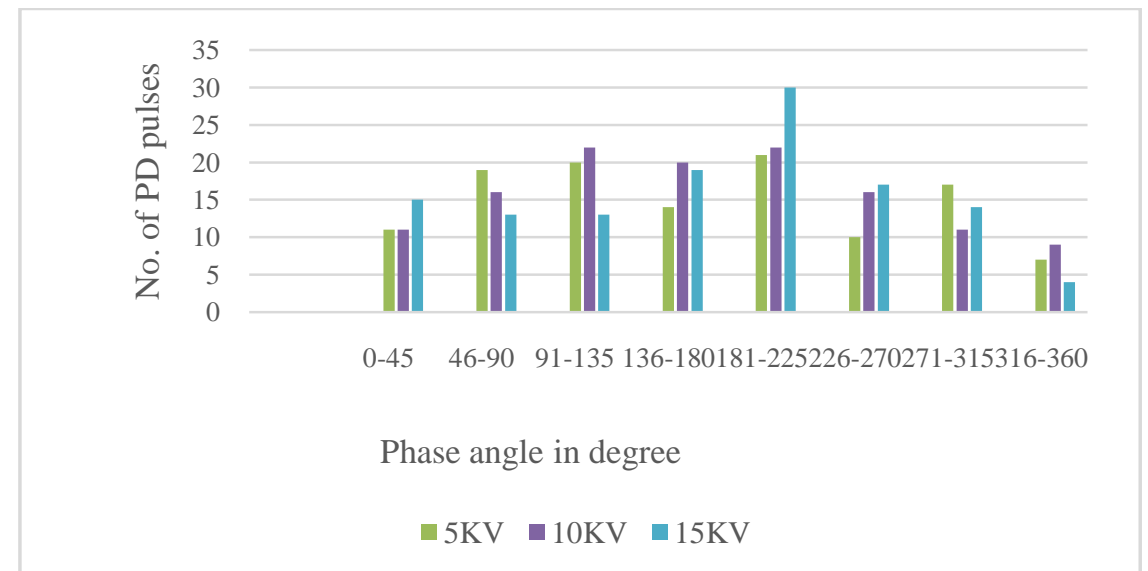

Fig13. No of PD pulse at different phase angles and different applied voltages of Teflon

It is observed that for Rubber the PD pulse are greater at $15 \mathrm{KV}$ for the phase angles $226^{\circ}$ to $360^{\circ}$. But for phase angles less than $225^{\circ}$ the no of PD pulse at $10 \mathrm{KV}$ is greater.

It is observed that the PD activity is higher for applied voltage of $15 \mathrm{kV}$ when compared to the PD activity for applied voltages $5 \mathrm{kV}$ and $10 \mathrm{kV}$. Also there is decrease in the number of PDs in case of applied voltage being $15 \mathrm{kV}$ after phase angle exceeds $315^{\circ}$ as indicated from figure 9 and 10.

Table6. No of PD pulse at different applied voltages at 10KV for epoxy resin, Rubber and Teflon

\begin{tabular}{|l|l|l|l|}
\hline \multirow{2}{*}{ Phase angle in degree } & \multicolumn{3}{l|}{ No.of PD pulses at 10k } \\
\cline { 2 - 4 } & Epoxy resin & Rubber & Teflon \\
\hline $0-45$ & 13 & 9 & 11 \\
\hline $46-90$ & 15 & 22 & 16 \\
\hline $91-135$ & 11 & 12 & 22 \\
\hline $136-180$ & 13 & 31 & 20 \\
\hline $181-225$ & 24 & 30 & 22 \\
\hline $226-270$ & 20 & 16 & 16 \\
\hline $271-315$ & 25 & 17 & 11 \\
\hline $316-360$ & 2 & 5 & 9 \\
\hline
\end{tabular}

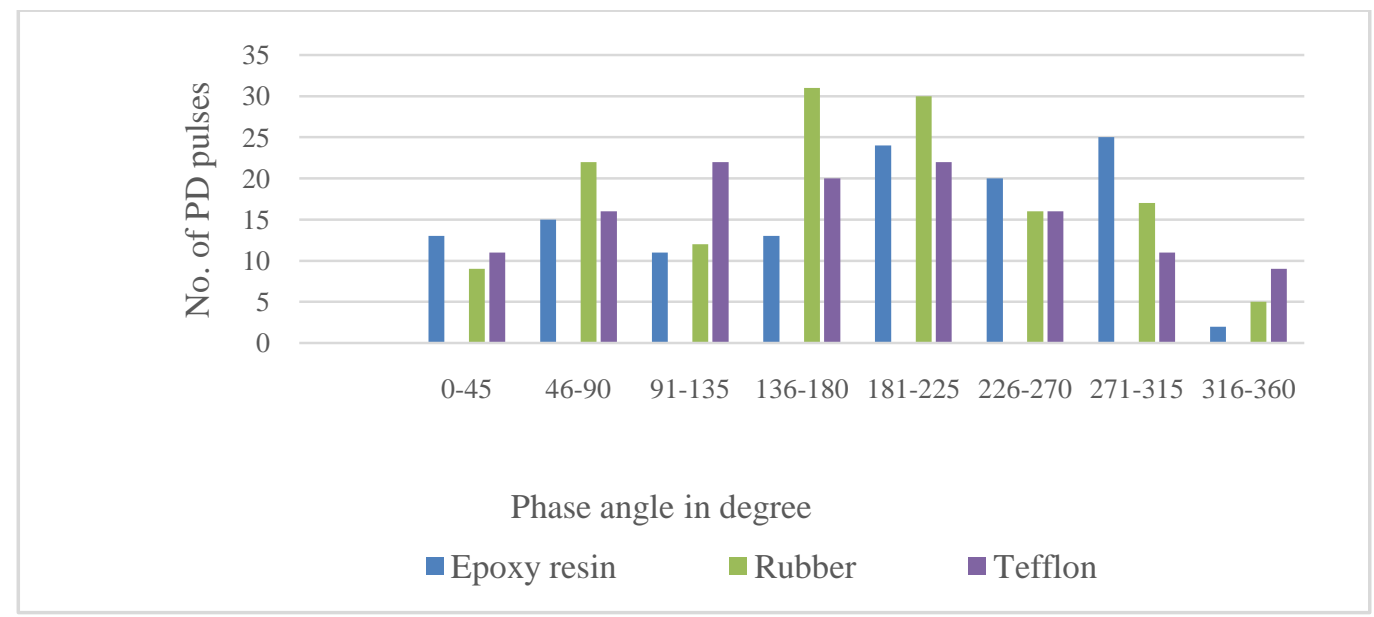

Fig 14.No. of PD pulse at different phase angles at 10KV for different solid dielectrics

At $10 \mathrm{KV}$ the no of PD pulse are greater between $46^{\circ}$ to $225^{\circ}$ for Rubber is more when compared to other two dielectrics . But for same voltage of $10 \mathrm{KV}$ between phase angle more than $226^{\circ}$ the no. of PD pulse for epoxy resin is more but it reduces after $315^{\circ}$. 
Voltage across the test object $(\mathrm{Vc})$ is measured and applied to a subsystem in MATLAB simulink created as per the formula below.

Voltage across the cubical void Cc is given by

$\mathrm{V}_{\mathrm{c}}=\frac{V_{a} * C_{b}}{C_{a}+C_{b}}$

The apparent charge transferred is calculated by

$\mathrm{Q}=V_{c} * C_{a}$

Table7. Apparent charge transfer at different applied Voltage for different dielectrics

\begin{tabular}{|l|l|l|l|}
\hline \multirow{2}{*}{ Applied voltage in KV } & \multicolumn{3}{|l|}{ Apparent charge in pC } \\
\cline { 2 - 4 } & Epoxy resin & Rubber & Teflon \\
\hline 5 & 0.361 & 0.309 & 0.206 \\
\hline 10 & 0.721 & 0.618 & 0.412 \\
\hline 15 & 1.08 & 0.927 & 0.618 \\
\hline 20 & 1.44 & 1.236 & 0.824 \\
\hline 25 & 1.8 & 1.545 & 1.03 \\
\hline 30 & 2.16 & 1.854 & 1.236 \\
\hline
\end{tabular}

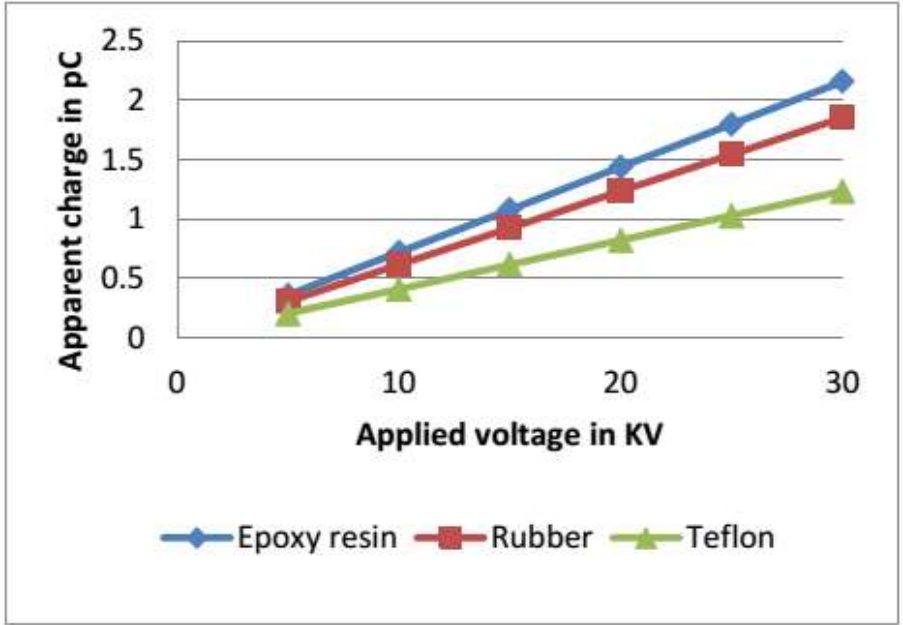

Fig 15.Apparent charge for different applied voltages of different solid dielectrics

We can see that from the graph the no. of apparent charges are more for epoxy resin when compared to other two dielectrics for the same applied voltages of $5 \mathrm{KV}, 10 \mathrm{KV}, 15 \mathrm{KV}, 20 \mathrm{KV}, 25 \mathrm{KV}, 30 \mathrm{KV}$.

We can also that from Fig15. the apparent charge transfer increases linearly as the input voltage increases[7].

\section{CONCLUSION}

Insulation is one of the most important parts of highvoltage instruments. Failure of insulation means failure of entire instrument, therefore it is necessary to pay attention to it. Partial discharge is one of the main causes for the insulation failure in HV systems instead of ageing ,progressive deterioration and then ultimate failure[3] .Hence detection and measurement of it is necessary to keep the power equipment in healthy condition during their operation. Its major sources are impurities and voids inside the insulation material. In this study, three different insulation materialshave been taken to obtain the partial discharge pattern. All sample considered for the simulation are cuboidal and the void in each sample is cubical. Each insulation material has different permittivity or dielectric strength and hence their void model capacitances are also different, due to which different partial discharge pattern has been obtained for different material at different voltage. The study shows that the permittivity of the insulation material is also an important parameter of partial discharge. It shows that partial discharge is the function of permittivity of the insulation material, void geometry enclosed in the insulation. All the simulation is done on MATLAB software package. It can be further extended to derive the other parameters on which partial discharge depends and can be made more accurate. 


\section{REFERENCES}

[1] High-voltage test techniques - Partial dischargemeasurements, 3rd ed. Geneva, IEC, 60270: 2000.

[2] J. R. Lucas, High Voltage Engineering, Sri Lanka,2001 Revised Edition 2001

[3] S. Karmakar and A. Sabat, "International Journal On Electrical Engineering an Informatics,"SimulationOf Partial Discharge in High Voltage PowerEquipment, vol . 3, Nov. 2, 2011.

[4] F. H. Kreuger, Partial Discharge Detection in High-Voltage Equipment, London, United Kingdom: Butterworths \& co Ltd, 1989.

[5] E. Kuffel, W. S. Zaengl and J. Kuffel, Highvoltage engineering:fundamentals, second ed., Eleslever, 2005.

[6] Sunil kumar, Harisha K S, Gouthami N, HarshithaV,Madhu"Partial Discharge Analysis of a Solid Dielectric Using MATLAB Simulink" InternationalJournal of Innovative Research in Electrical, Electronics, Instrumentation And Control Engineering vol. 4, issue 6, June 2016.

[7] R. Bartnikas, "Partial Discharge their mechanism, Detection and Measurement," IEEE Trans. Electr.Insul., vol. 9, pp. 763-808, 2002.

[8] Deepak Kumar, Dr. Ranjana Singh, "Simulation of Partial Discharge for Different Insulation Material Using MATLAB", IJSRD International Journal for Scientific Research \& Development, Vol. 3, Issue 04, 2015.

\section{BIOGRAPHIES}

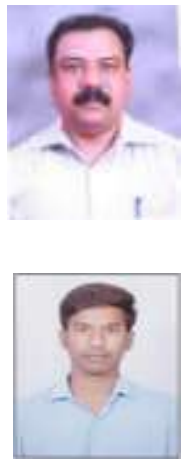

D.M. Srinivasa completed engineering from BIET, Davangere and Master's degree from MCE, Hassan and presently pursuing Ph.D.in university of Mysore, Mysore and working as Assistant professor in PESCE, Mandya, Karnataka, India from 2008.

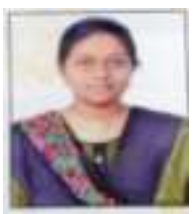

Flavia Valentina was bornon $18^{\text {th }}$ August 1995. Currently pursuing B.E degree in Electrical and Electronics Engineering in PESCE, Mandya, Karnataka, India.

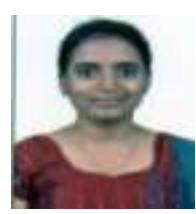

Chandrakanth B was bornon $13^{\text {th }}$ August 1995. Currently pursuing B.E degree in Electrical and Electronics Engineering in PESCE, Mandya, Karnataka, India.

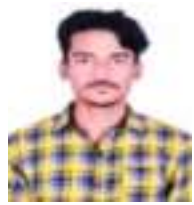

Suneel was bornon $28^{\text {th }}$ June 1990. Currently pursuing B.E degree in Electrical and Electronics Engineering in PESCE, Mandya, Karnataka, India. 